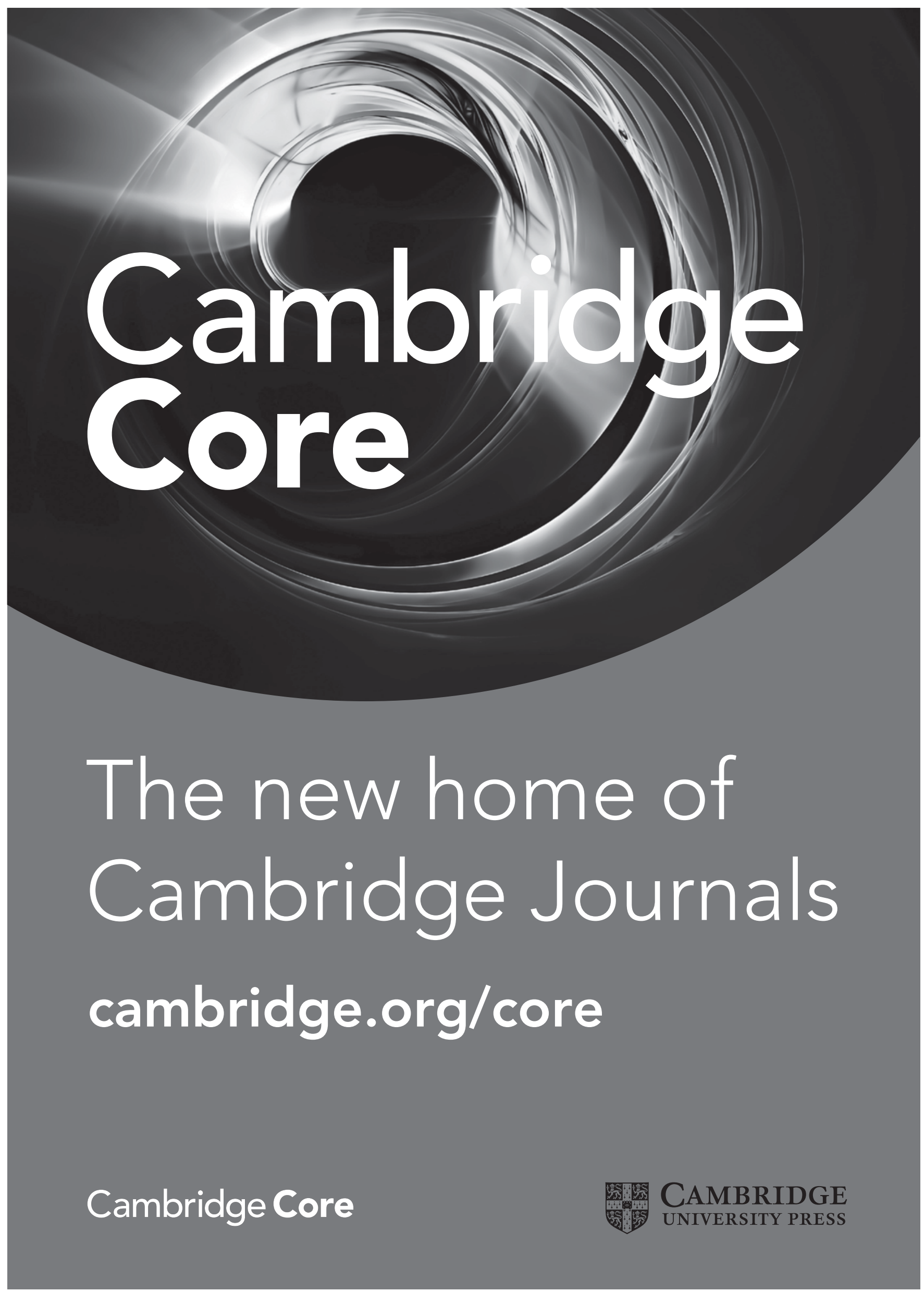




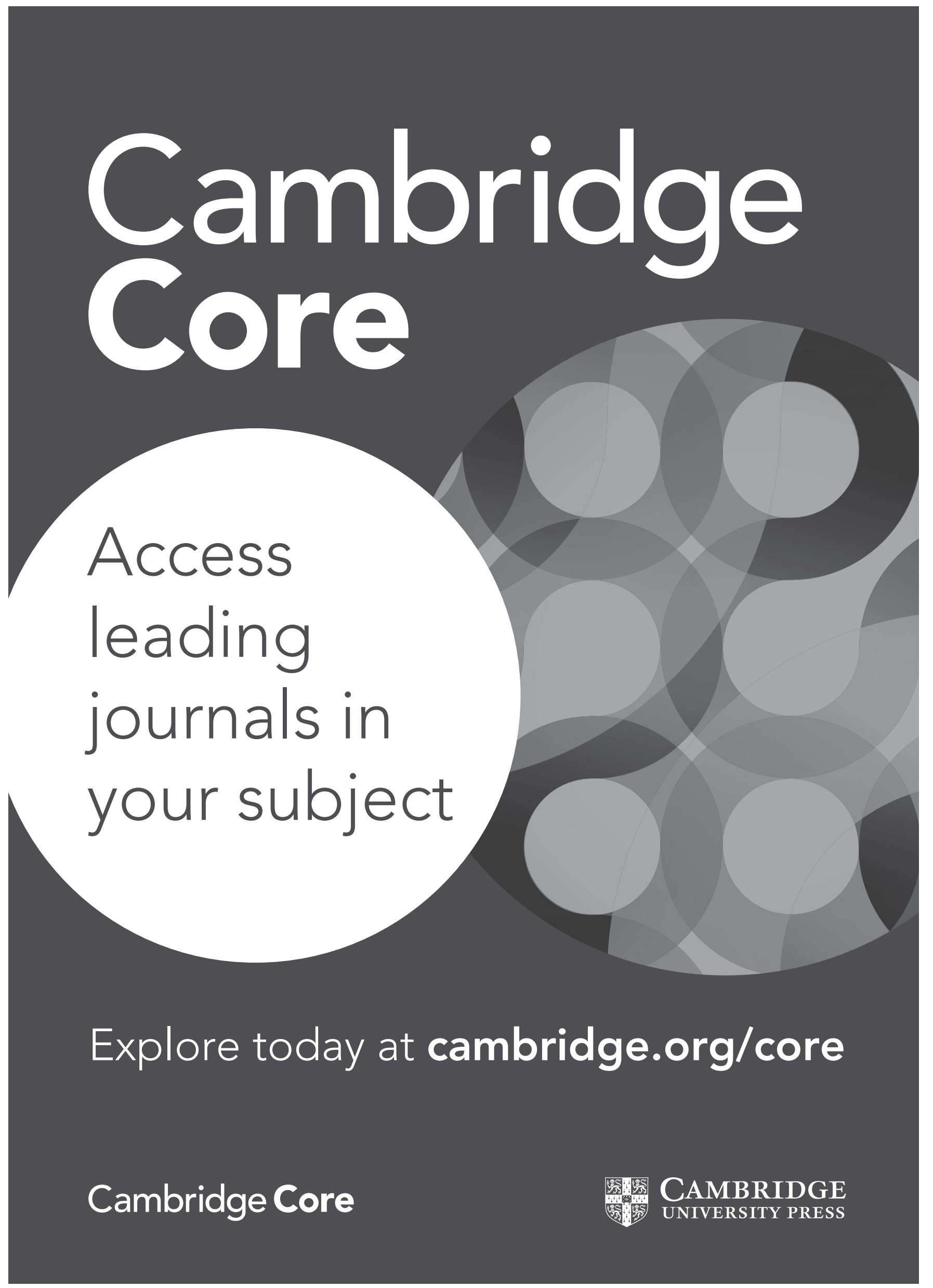




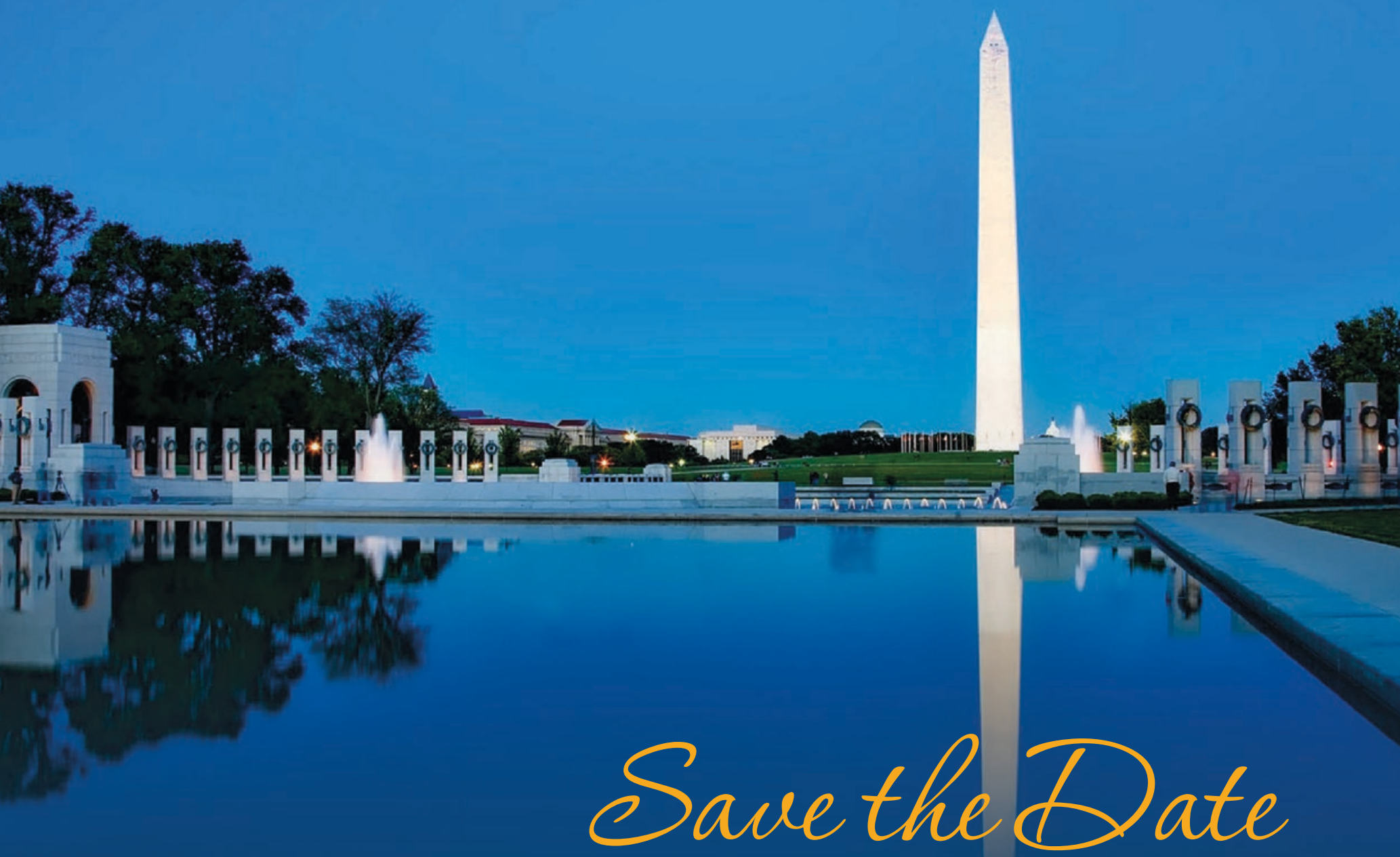

Don't miss the premier international infectious diseases meeting of the year

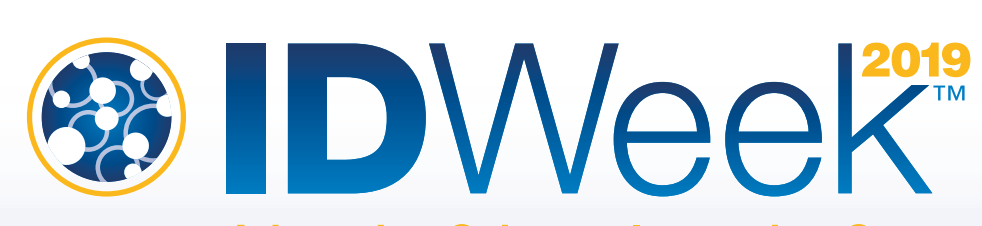

Advancing Science, Improving Care

October 2-6, 2019

Washington, DC

www.idweek.org 


\section{Practical Healthcare}

\section{FOURTH EDITION}

\section{Epidemiology}

Editors:

Ebbing Lautenbach, University of Pennsylvania School of Medicine

Preeti N. Malani, University of Michigan, Ann Arbor Keith F. Woeltje, Washington University School of Medicine, St Louis

Jennifer H. Han, University of Pennsylvania School of Medicine

Emily K. Shuman, University of Michigan, Ann Arbor Jonas Marschall, Washington University School of Medicine, St Louis

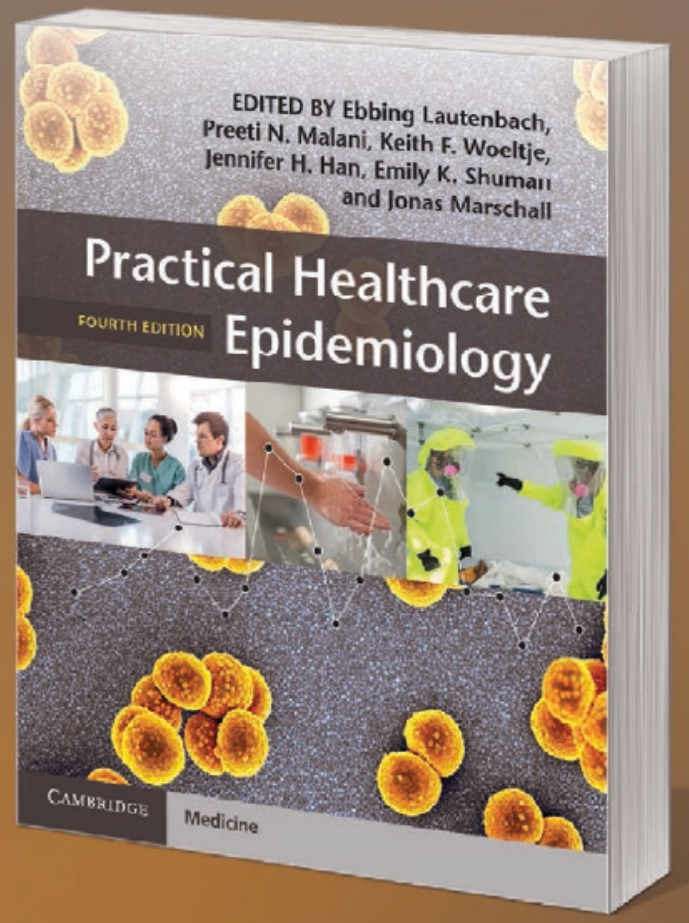

May 2018 / Hardback / 9781107153165 $\$ 185.00 / £ 145.00$
Practical Healthcare Epidemiology takes a handson approach to infection prevention for physicians, healthcare epidemiologists, infection preventionists, microbiologists, nurses, and other healthcare professionals. Increased regulatory requirements and patient knowledge and involvement has elevated patient safety, healthcare-associated infections, antibiotic stewardship and quality-of-care to healthcare wide issues. This fully updated new edition brings together the expertise of leaders in healthcare epidemiology to provide best practice expert guidance on infection prevention for adult and pediatric patients in all types of healthcare facilities, from community hospitals and academic institutions, to long-term care and resource limited settings. Written in clear, straightforward terms to address prevention planning and immediate responses to specific situations, this is the go-to resource for any practitioners in medicine or public health involved in infection prevention, regardless of their current expertise in the field.

- In light of headline grabbing outbreaks like Ebola, the important subject of infection prevention and control in healthcare settings is more topical than ever

- The chapters of this book are clear and succinct, making excellent use of charts, graphs, and bulleted lists to guide the reader to essential information

- Provides a resource both for those new to the field and foundation of best practices across the healthcare continuum for specialists 